\begin{tabular}{|c|c|c|}
\hline & Mansoura University \\
Faculty of Engineering \\
Mansoura Engineering Journal
\end{tabular}

\title{
Effect of Rice Husk Ash on the Performance of Hot Asphalt Mixes

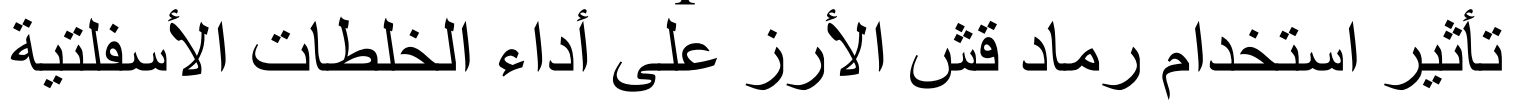 में
}

\author{
Mohamed Mohiey, Hassan A. Mahdy and Mokhtar F. Ibrahim
}

\begin{abstract}
KEYWORDS:
Rice Husk Ash, Hot Asphalt Mixes, Dynamic Modulus (E*), Marshall Test, Rut Depth, Indirect Tensile Strength.
\end{abstract}

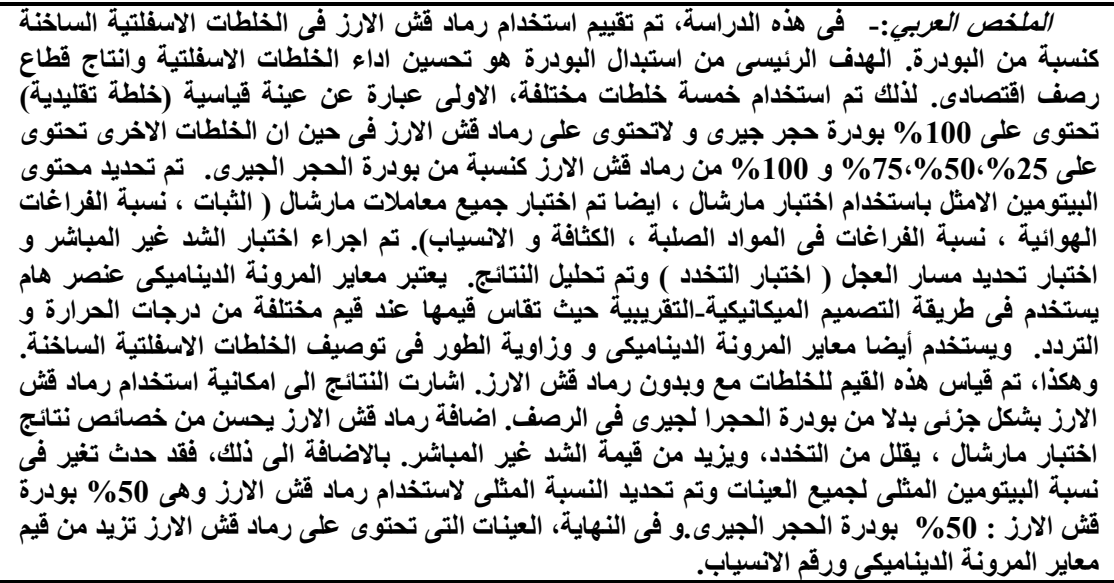

Abstract - In this paper, using rice husk ash (RHA) in hot mix asphalt (HMA) as filler was evaluated. The main aim of replacing mineral filler is enhancing the performance of asphalt mixes and producing an economical asphalt mix. For this purpose, five different mixes were prepared; the first was a control mix (traditional mix) containing $\mathbf{1 0 0 \%}$ Lime Stone Dust (LSD) as filler and $0 \%$ RHA. While, the other mixes contain $25 \%, 50 \%$, $75 \%$ and $100 \%$ of RHA as a percentage of the filler weight. Optimum bitumen content (OBC) was determined using 2020

Received: 4 May, 2020 - Revised: 16 June, 2020 - Accepted: 16 June,

Mohamed Mohiey Eldien Helal, M.sc Student, Civil Engineering, High Institute of Engineering- El Shorouk Academy, Egypt.

(E-mail: mohamedmohiey50@gmail.com).

Hassan Abd-elzaher Mahdy, Professor. of Highway and Airport Engineering, Public Works Department, Faculty of Engineering, Ain Shams University, Egypt. (E-mail: Drhassanmahdy@gmail.com).

Mokhtar Fahmy Ibrahim, Lecturer of Highway and Traffic Engineering, Civil Engineering, High Institute of Engineering - El Shorouk Academy, Egypt.(E-mail: mokhtargendy91@gmail.com).
Marshall test, also all Marshall parameters (Stability, Air Voids, Voids in Mineral Aggregate, Unit Weight and Flow) were examined. Indirect Tensile Strength Test (ITST) and Wheel Tracking Test (WTT) were conducted and their results were analyzed. Dynamic modulus $\left(\left|\mathrm{E}^{*}\right|\right)$ is considered an important parameter used in mechanistic-empirical pavement design. The $\left|E^{*}\right|$ is measured at different temperature/frequency combinations. Dynamic modulus $\left(\left|E^{*}\right|\right)$ and phase angle $(\delta)$ are used for the visco- elastic characterization of HMA. Thus, these properties were measured for mixes with and without RHA. The results indicate that RHA has the potential to be used as partial substitution of mineral filler LSD in pavement construction. Adding RHA enhances Marshall stiffness, reduces rut depth and increases indirect tensile strength values. Further, a significant change has been occurred in $\mathrm{OBC}$ for all mixes and the optimum replacement ratio is recorded as 50\% RHA: 50\% LSD. Finally, mixes containing RHA show higher dynamic modulus values and flow number. 


\section{INTRODUCTION AND BACKGROUND}

$\mathrm{D}$ UE to continuous increase in traffic volume and percentage of trucks with heavy loads, as well as tire pressure many researchers reported an increase in pavement distresses such as rutting, surface wear and cracks even for newly constructed roads. In addition, the maintenance efforts have been exceeded and the traffic flow during maintenance period has also been affected. Thus, enhancing the asphalt mixes performance becomes essential. Different methods used to enhance the HMA properties are proposed and uses such as additives.

On the other hand, burning rice husk is one of the most environmental problems in Egypt. It has negative effects on human health and life. Burning the rice husk is the main cause of what is called "black cloud", which has negative influences on the environment and human health. Thus, in this research, RHA was used in asphalt mixes as a replacement of mineral filler to reduce LSD consumption and improve the engineering properties of HMA. Also, consume a certain amount of RHA in asphalt mixes and thus reduces the effect of black cloud.

Different factors affect rutting and cracking of asphalt concrete mixes, some of these factors are vehicle speed, vehicle axel load, tire pressure, compaction, thickness of pavement and climatic conditions. Also, asphalt mix type plays a major role in the performance of pavement. It was found that stone mastic asphalt (SMA) mixture has more resistance against rutting as compared to dense graded mixture, because it consists of coarse aggregate skeleton as well as higher asphalt content which provide Stone-on-Stone contact among the coarse aggregate particles[1,2].

Many researches indicated that, using asphalt additives enhanced the pavement resistance to some types of distresses while other additives caused or increased other types of distresses. In addition, adding Rice Husk Ash (RHA) to the HMA is evaluated in various researches.

Various studies investigated the effect of using RHA in hot asphalt mixes, some of them used RHA as a percentage of the filler in traditional mixes[3, 4]. Also using RHA as filler in Recycling of Reclaimed Asphalt Pavement (RAP) was evaluated[5]. Another study evaluated the feasibility of using copper slag (CS) and recycled concrete aggregate (RCA) as substitutes for virgin aggregate in modifying the gradation of cold recycled mixes made with RAP material. Nine different types of mixtures containing three types of aggregates (limestone (LS), CS, and RCA) and three types of additives (cement, fly ash, rice husk ash) were used. As well, three types of mixtures without additive were used to study the effects of different aggregates and additives on the mechanical properties of Cold in Place Recycled (CIR) mixes[6]. The investigation of the effect of using RHA as a binder modifier on hot mix asphalt was tried. Bitumen blended with 5\%,10\%, $15 \%$ and $20 \%$ of RHA [7]. Mistry R. et al. [8] studied the effect of using RHA in enhancing HAM properties. The study used RHA, hydrated lime and fly ash as filler. The results noted that RHA showed a greater affinity to the bitumen attributing the highest stiffening effect of the bituminous mastic droplets compared to that of other used fillers. Another research investigated the effect of crumb rubber powder (CRP) and RHA on HMA by using them as binder modifiers. RHA and CRP have been combined to perform mixes, Various percentages of RHA (1\%, 4\% and 7\%) and CRP (5\%, $10 \%$, and $15 \%$ ) were employed for the preparation of modified asphalt by asphalt binder weight. Other mixes were prepared using only one modifier, RHA or CRP with the same ratios above and then compared to the first Mix. The (RHA + CRP) modified asphalt binder showed better efficiency relative to modified RHA or CRP asphalt binder[9]. Another research evaluated the performance of mastics and SMA mixture containing coal waste ash CWA and RHA in different ratios $(0 \%, 25 \%, 50 \%, 75 \%$ and $100 \%)$ as a replacement of LSD as conventional filler. Various tests were carried out on the mixture such as Marshall stability, wheel tracking test, ITS test, resilient modulus and moisture resistance. The results indicated that the properties of modified mixtures had been enhanced compared to control mixture[10]. Several researches studied using RHA in enhancing the engineering properties of HMA and a significant improvement was found [11-13]. Thus, the aim of this study is evaluating the effect of RHA on the engineering properties of HMA.

\section{MATERIALS}

Two types of fillers were used in this study, limestone dust (LSD) and RHA as a replacement of LSD in asphalt mixes. The properties of all used materials are presented in the following section.

\section{A. Aggregate}

The coarse aggregate used in this research are crushed stones from dolomite. The physical properties and gradation of the used fine and coarse aggregate are shown in Tables (1) and (2) for the wearing surface (4C) dense graded mix.

\begin{tabular}{|c|c|c|c|c|c|c|c|}
\hline Property & $\begin{array}{c}\text { AASHTO } \\
\text { Designation No. }\end{array}$ & $\begin{array}{c}\text { Coarse } \\
\text { Aggregate } \\
\text { Size (1) }\end{array}$ & $\begin{array}{r}\text { TABI } \\
\text { AGGREGATE } \\
\text { Coarse } \\
\text { Aggregate } \\
\text { Size (2) } \\
\end{array}$ & $\begin{array}{l}\text { ERTIES } \\
\text { Fine Aggregate } \\
\text { (Crushed Sand) }\end{array}$ & $\begin{array}{l}\text { Fine Aggregate } \\
\text { (Natural Sand) }\end{array}$ & $\begin{array}{l}\text { Mineral Filler } \\
(\mathrm{MF})\end{array}$ & $\begin{array}{l}\text { AASHTO } \\
\text { Limits }\end{array}$ \\
\hline Bulk (S.G) & $\begin{array}{c}\text { AASHTO } \\
(85-77)\end{array}$ & 2.480 & 2.402 & 2.720 & 2.620 & 2.75 & -------- \\
\hline Apparent (S.G) & $\begin{array}{c}\text { AASHTO } \\
(85-77)\end{array}$ & 2.605 & 2.601 & ------- & ------- & ------ & ---------- \\
\hline $\begin{array}{c}\% \text { Water } \\
\text { absorption }\end{array}$ & $\begin{array}{c}\text { AASHTO } \\
(85-77)\end{array}$ & 1.80 & 3.10 & ------- & ------- & ------- & $5 \operatorname{Max}$ \\
\hline
\end{tabular}


TABLE 2

\begin{tabular}{|c|c|c|c|c|}
\hline \multirow{3}{*}{$\begin{array}{l}\text { Sieve Size } \\
\text { (Inch) }\end{array}$} & \multicolumn{2}{|c|}{ AGGREGATE GRADATIOI } & \multirow{2}{*}{\multicolumn{2}{|c|}{ Specification Limits (4C-Mix) }} \\
\hline & Sieve Size & \multirow{2}{*}{$\%$ Passing } & & \\
\hline & $(\mathrm{mm})$ & & Lower & Upper \\
\hline $1 "$ & 25.40 & 100 & 100 & 100 \\
\hline $3 / 4 "$ & 19.00 & 86.10 & 80 & 100 \\
\hline $3 / 8^{\prime \prime}$ & 9.50 & 65.90 & 60 & 80 \\
\hline No. (4) & 4.75 & 49.00 & 48 & 65 \\
\hline No. (8) & 2.36 & 42.70 & 35 & 50 \\
\hline No. (30) & 0.60 & 28.50 & 19 & 36 \\
\hline No. (50) & 0.30 & 16.40 & 13 & 23 \\
\hline No. (100) & 0.15 & 8.50 & 7 & 15 \\
\hline No. (200) & 0.075 & 6.20 & 3 & 8 \\
\hline
\end{tabular}

\section{B. Asphalt Binder}

The asphalt cement used in this study is obtained from Suez. Asphalt cement grade is $60 / 70$, with specific gravity
1.02 which is widely used in pavement construction in Egypt. The consistency properties tests of the asphalt binder are carried out and the results are shown in Table (3).

TABLE 3

AsPhalt CEMENT PRoperties

\begin{tabular}{l||l||l||l} 
Property & AASHTO Designation No. & Result & Specifications Limits \\
\hline Penetration at $25^{\circ} \mathrm{C}, 0.1 \mathrm{~mm}$ & T- 49 & 63 & $60-70$ \\
\hline Kinematic Viscosity, mm2/s & T- 201 & 367 & $\geq 320$ \\
\hline Flash point, ${ }^{\circ} \mathrm{C}$ & T-48 & 264 & $\geq 250$ \\
\hline Softening point, ${ }^{\circ} \mathrm{C}$ & T-53 & 47 & $45-55$
\end{tabular}

\section{Rice Husk Ash}

The used RHA in this study was prepared by burning rice husk at a temperature $700{ }^{\circ} \mathrm{C}$.; the burning process was carried out by putting the rice husk in the oven for approximately 2 hours. The color for the gathered ash was medium grayish and light mauve and its specific gravity is 2.71 . When the oven temperature decreased to $150{ }^{\circ} \mathrm{C}$., the ashes were removed from the oven to cool down. Figure (1) shows both raw and burned RHA.

Also, the chemical composition of the used RHA is presented in Table (4), while the results of XRD test of RHA is shown in Figure (2). XRD patterns of the prepared samples show a crystalline sharp peak at $2 \theta=22$ with a number of less intense peaks at $2 \theta=28,32,47,43,47,54$ and 58. All the peaks are well described by the cristobalite pattern superimposed on a broad background caused by the remaining amorphous phase. From the figure it was found that RHA contains a higher value from $\mathrm{SiO}_{2}$ about $82 \%$. Also sieve analysis of LSD and RHA are presented in Table (5).

TABLE 4

\begin{tabular}{l||l||l||l||l||l||l||l}
\multicolumn{1}{l}{$\begin{array}{l}\text { Chemical } \\
\text { Composition }\end{array}$} & $\mathrm{SiO} 2$ & $\mathrm{~A} 12 \mathrm{O} 3$ & $\mathrm{Fe} 2 \mathrm{O} 3$ & $\mathrm{CaO}$ & $\mathrm{MgO}$ & $\mathrm{Mn} 2 \mathrm{O} 3$ & Others \\
\hline Percentage \% & 82.3 & 4.05 & 1.64 & 9.54 & 2.08 & 0.25 & 0.14
\end{tabular}

TABLE 5

\begin{tabular}{|c|c|c|c|c|}
\hline \multirow{3}{*}{$\begin{array}{l}\text { Sieve Size } \\
\text { (Inch) }\end{array}$} & \multirow{3}{*}{$\begin{array}{l}\text { Sieve Size } \\
(\mathrm{mm})\end{array}$} & SIEVE ANALYS & AND RHA & \multirow{3}{*}{ Specification Limits $\%$} \\
\hline & & LSD & RHA & \\
\hline & & \multicolumn{2}{|c|}{$\%$ Passing } & \\
\hline No. 30 & 0.6 & 100 & 100 & 100 \\
\hline No. 100 & 0.15 & 89.5 & 100 & $\geq 85$ \\
\hline No. 200 & 0.075 & 72.8 & 100 & $\geq 65$ \\
\hline
\end{tabular}




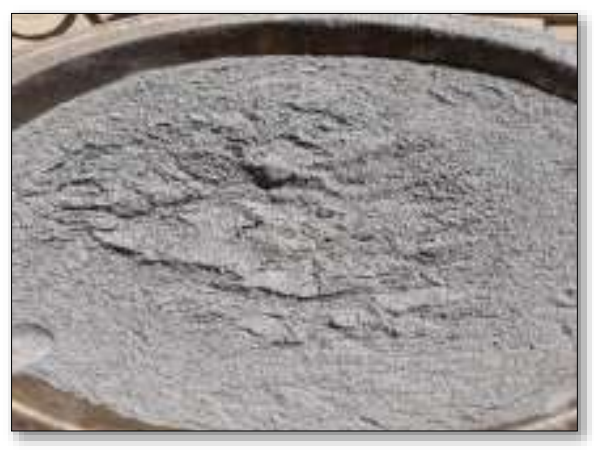

a: burned RHA

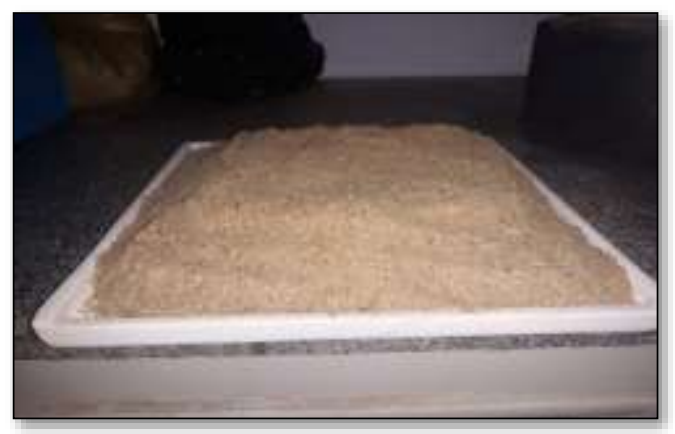

b: Raw RHA.

Fig. 1. RHA, a: burned RHA\& b: Raw RHA

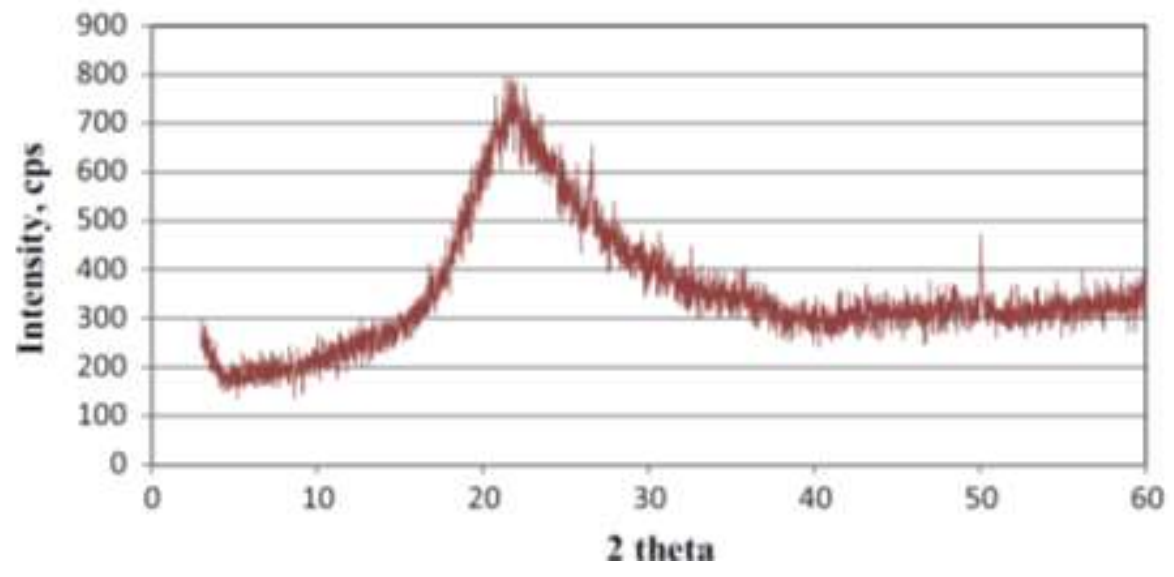

Fig. 2. RHA XRD Image

\section{EXPERIMENTAL PROCEDURE AND TESTING:}

\section{A. Marshall Test}

Marshall test was performed in accordance with ASTM D6927-15 [14]. The purpose of test aims to determine Marshall parameters as stability, flow and then Marshall Quotient (MQ). MQ can be calculated by the following equation[15].

$$
\text { Marshall Quotient }(M Q), \mathrm{kg} / \mathrm{mm}=\frac{\text { Marshall Stability }}{\text { Marshall flow }}
$$

Marshall test results as Stability, Flow, Air voids (AV \%), Voids in mineral aggregate (VMA \%) and Unit weight were evaluated for both control and modified mixtures. The modified mixtures contain replacement ratios of RHA as $25 \%$, $50 \%, 75 \%$ and $100 \%$ of RHA. In this test, at least 3 specimens were prepared for each bitumen percentage and compacted by 75 blows (heavy traffic) on each face of the specimen with a standard hammer falling from a specific height. After compaction, specimens were left for at least 24 hours then they are submerged in a water bath of $60^{\circ} \mathrm{C}$. for 30 to 45 minutes. The specimens were then placed in Marshall testing machine by which stability and flow for the specimens were measured.

\section{B. Moisture Susceptibility}

Resistance to moisture damage is one of the most important properties that must be available in an asphalt mixture. This property was investigated in this study in accordance with ASTM D1559-89 [16] . Five different Marshall specimens were prepared $(3 \times 5)$ using the same procedure as in Marshall test and the specimens were submerged in a water bath for 24 hours the samples were then tested following the same procedure of Marshall stability test. The retained Marshall stability or Loss of Stability (LOS) was calculated as percentage between the average stability of the second group of specimens (Submerged) over the average stability for the first group of specimens (Marshall Stability) as noted in the following equation:

$$
(L O S) \%=\left(1-\frac{\text { Stability of Wet Specimens }}{\text { Stability of Dry Specimens }}\right) \times 100
$$

\section{Indirect Tensile Strength Test}

Indirect Tensile Strength (ITS) test was performed on both the control and modified specimens in accordance with ASTM D6931 [17] test procedure. ITS test is directly related to the pavement cracking properties. The indirect tensile strength test involves loading a cylindrical specimen with compressive loads which act parallel to and along the vertical diametrical plane. This loading configuration develops a relatively 
uniform tensile stress perpendicular to direction of the applied load along the vertical diametrical plane. This tensile strength causes the specimen to fail by splitting or rupturing along the vertical diameter. ITS test is performed using Marshall Apparatus. The failure load for each specimen is recorded and the ITS value is calculated as follows [17]:

$$
I T S,(K P a)=\frac{2 F}{\pi H D}
$$

Where $\mathrm{F}$ is failure Load $(\mathrm{KN}), \mathrm{H}$ is specimen thickness $(\mathrm{m})$ and $\mathrm{D}$ is specimen diameter $(\mathrm{m})$.

Tensile Strength Ratio (TSR), this property was investigated in this study. This test is used to determine the effect of saturation and accelerated water conditioning on the indirect tensile strength of cylindrical specimens. To conduct the test, six specimens from each mixture were prepared and grouped equally into conditioned and dry specimens. The test was performed in accordance with ASTM D4867 [18]. All the samples were tested at a constant temperature of $25^{\circ} \mathrm{C}$ and the ITS values were measured for both dry and wet specimens. TSR is calculated using the following equation[18]:

$$
T S R=\frac{S_{t m}}{S_{t d}} x 100
$$

Where TSR is Tensile Strength Ratio (\%), $\mathrm{S}_{\mathrm{tm}}$ is wet strength or average tensile strength of the moistureconditioned specimens, $(\mathrm{kPa})$ and $\mathrm{S}_{\mathrm{td}}$ is dry strength or average tensile strength of the dry specimens, $(\mathrm{kPa})$.

\section{Wheel Tracking Test}

This test provides information about the rate of permanent deformation from a moving concentrated load in accordance with AASHTO T324[19]. A laboratory compactor has been designed to prepare slab specimens. The test used to determine the premature failure susceptibility of HMA due to weakness in the aggregate structure, inadequate binder stiffness, or moisture damage. This test measures the rut depth and number of passes or time to the final rut depth. The sample is prepared by first mixing the ingredients at the appropriate mixing temperature then compacting the mixes by a steel roller weights $53 \mathrm{Kg}$ for 14 cycles then left the specimen to cool for 24 hours. Five samples were prepared with dimensions $30.5 \times 30.5 \times 5 \mathrm{~cm}$. The specimens were tested at $60^{\circ} \mathrm{C}$.

\section{E. Dynamic Modulus (|E*|) and Flow Number Tests}

Dynamic (complex) modulus is a critical parameter used in evaluating the performance of asphalt mixes under different temperatures and frequencies. The test was performed in accordance with AASHTO TP62 [20]. The dynamic modulus $\left|\mathrm{E}^{*}\right|$ is one of the parameters used to evaluate both of rutting and fatigue cracking distresses predictions in the Mechanistic - Empirical Pavement Design Guide (MEPDG). Many factors affect the dynamic modulus values as aggregate gradation, mixture air voids, binder shear dynamic modulus $\mathrm{G}^{*}$, binder viscosity, etc. Therefore, in this study, the test for both conventional and modified mixtures was performed. A flow number test was conducted at $54.4^{\circ} \mathrm{C}$ at a repeated compressive haversine loading (the one cycle with $0.1 \mathrm{~s}$ loading time and $0.9 \mathrm{~s}$ resting time) to measure the vertical accumulated permanent strains as a function of loading cycles after performing the $\mathrm{E}^{*}$ testing. The test gives an indication of rutting resistance; thus, it was performed on both control and modified mixtures.

\section{RESULTS AND DISCUSSIONS}

\section{A. Marshall Test Results}

The first step in Marshall test is determining the optimum bitumen content (OBC). In this research OBC values for all investigated mixtures (conventional and modified) were determined. Also, Marshall properties for both control and modified mixtures (25\%, 50\%, $75 \%$ and 100\%) were determined and reported as shown in Table (6). Also, figures (3) to (9) represent Marshal test results at different values of RHA.

\begin{tabular}{|c|c|c|c|c|c|c|}
\hline Property & Control Mix & $\begin{array}{r}\text { MAF } \\
25 \% \text { RHA }\end{array}$ & $\begin{array}{l}\text { EST RESUL7 } \\
\text { 50\%RHA }\end{array}$ & $75 \%$ RHA & $100 \%$ RHA & $\begin{array}{c}\text { Specification } \\
\text { Limits (Heavy } \\
\text { Traffic) } \\
\end{array}$ \\
\hline Stability $(\mathrm{Kg})$ & 1181 & 1212 & 1247 & 1305 & 1085 & Min. (900) \\
\hline Flow $(\mathrm{mm})$ & 2.47 & 2.35 & 2.59 & 2.56 & 2.73 & $2-4$ \\
\hline Air voids (VA) (\%) & 4.27 & 4.2 & 4.1 & 3.24 & 3.5 & $3-5$ \\
\hline Unit Weight $\left(\mathrm{gm} / \mathrm{cm}^{3}\right)$ & 2.313 & 2.314 & 2.305 & 2.322 & 2.317 & ---- \\
\hline VMA $(\%)$ & 15.07 & 15.1 & 15.45 & 15.11 & 15.2 & Min. 15 \\
\hline $\mathrm{OBC} \%$ & 5.0 & 5.10 & 5.20 & 5.50 & 5.40 & $3.50-7$ \\
\hline MQ (Kg/mm) & 477.5 & 515.74 & 481.4 & 524.7 & 397.4 & $\begin{array}{ll}---- \\
\end{array}$ \\
\hline
\end{tabular}

TABLE 6 


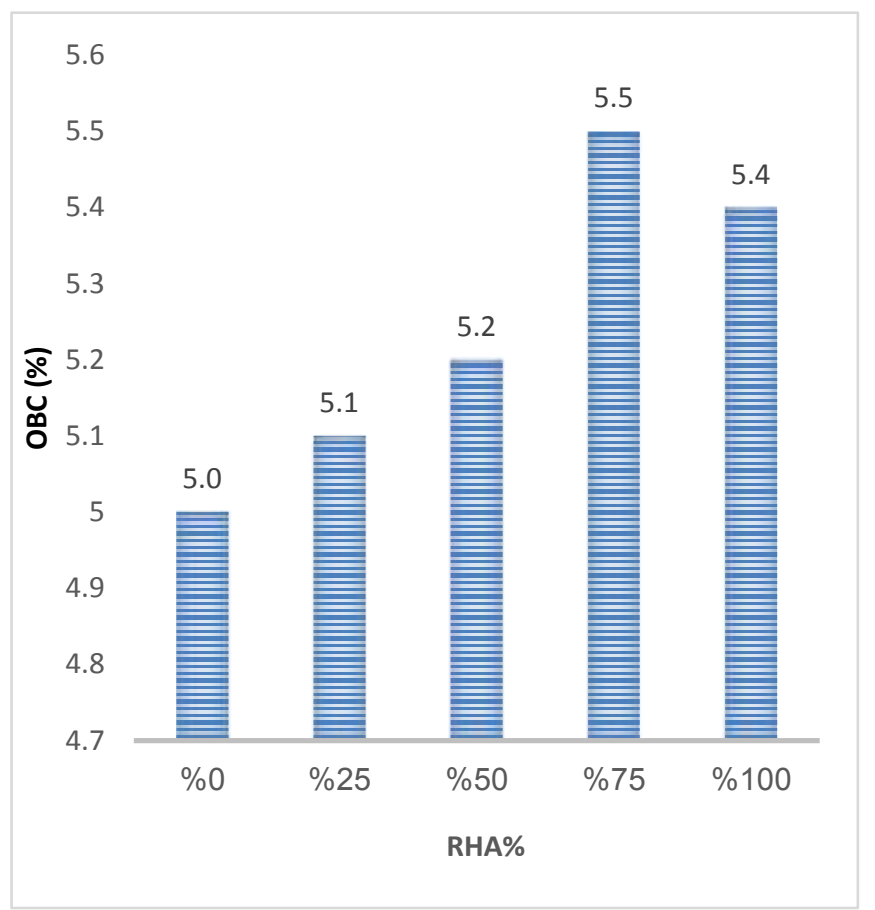

Fig. 3. OBC\% at different Values of RHA

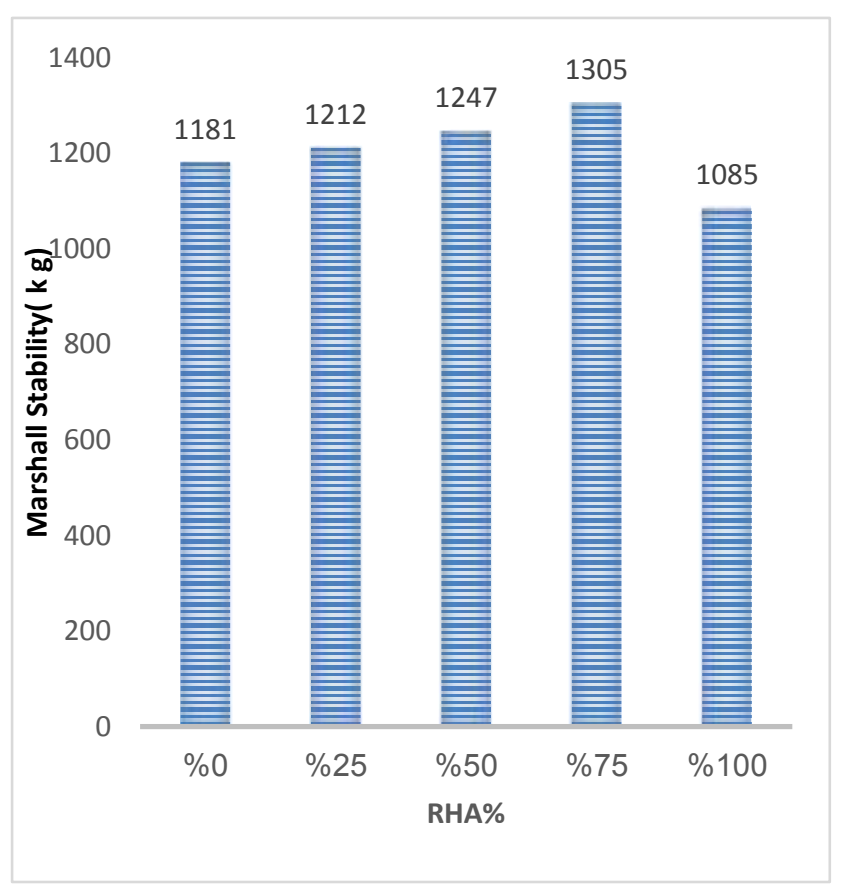

Fig. 4. \% RHA vs. Marshall Stability (Kg) at $\mathrm{OBC} \%$

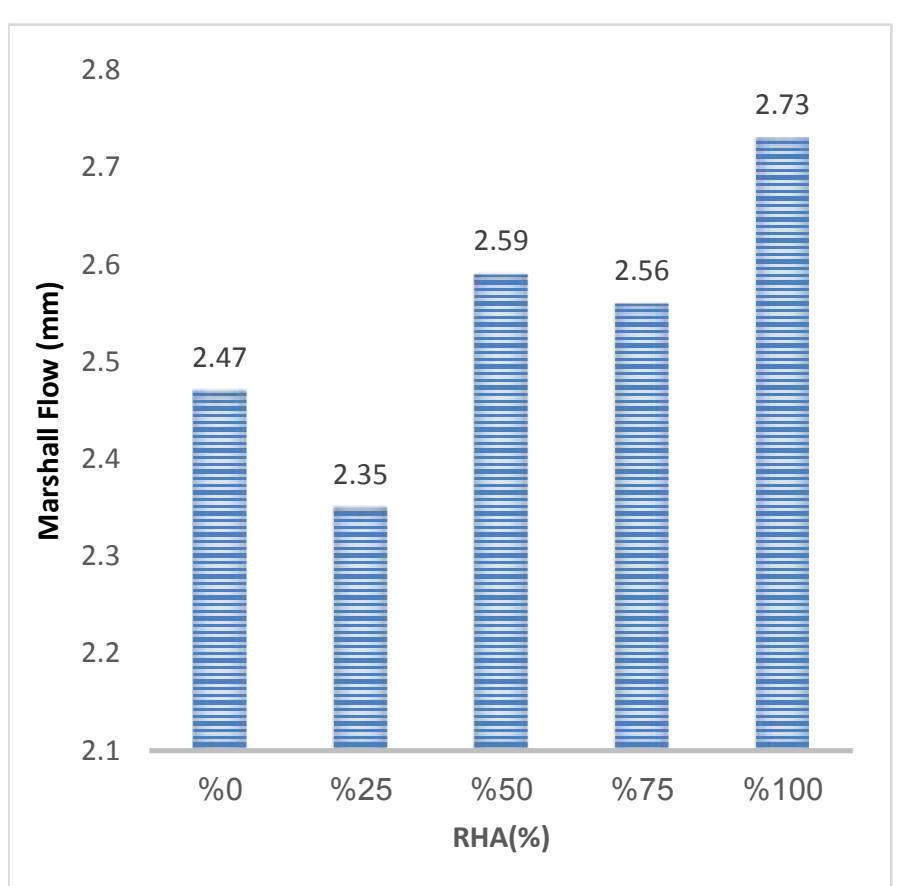

Fig. 5. \% RHA vs. Marshall Flow (mm) at OBC\%.

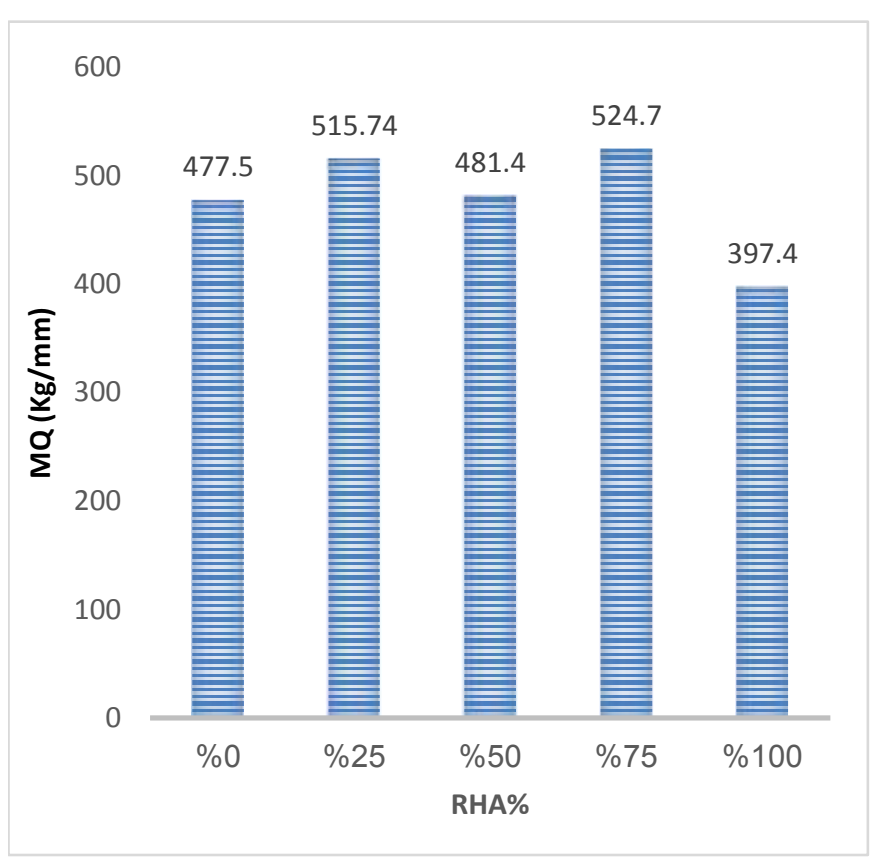

Fig. 6. \% RHA vs. MQ (Kg/mm) at $\mathrm{OBC} \%$ 


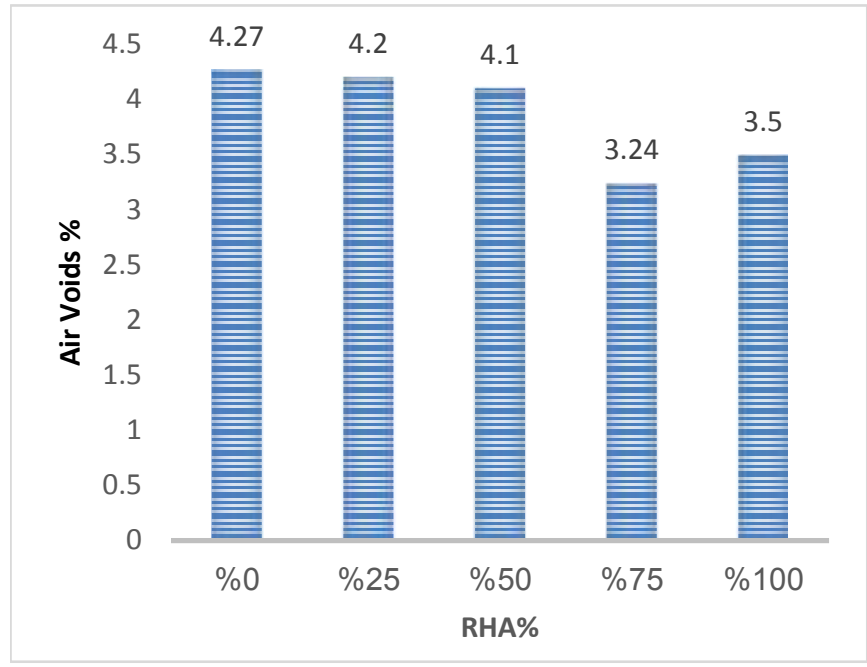

Fig. 7. \% RHA vs. Air Voids\% at OBC\%

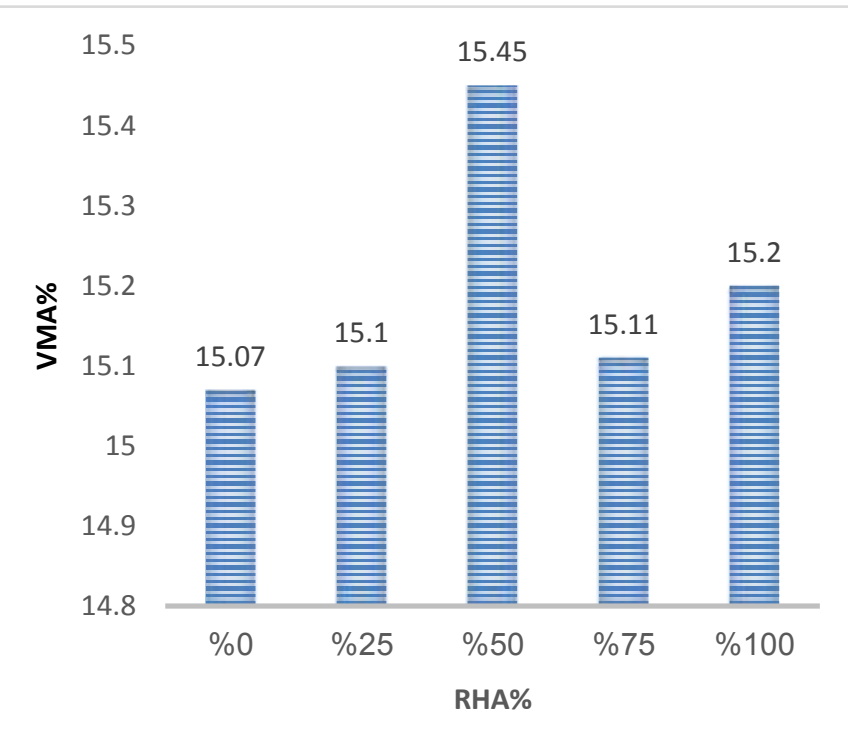

Fig. 8. \% RHA vs. VMA\% at $\mathrm{OBC} \%$

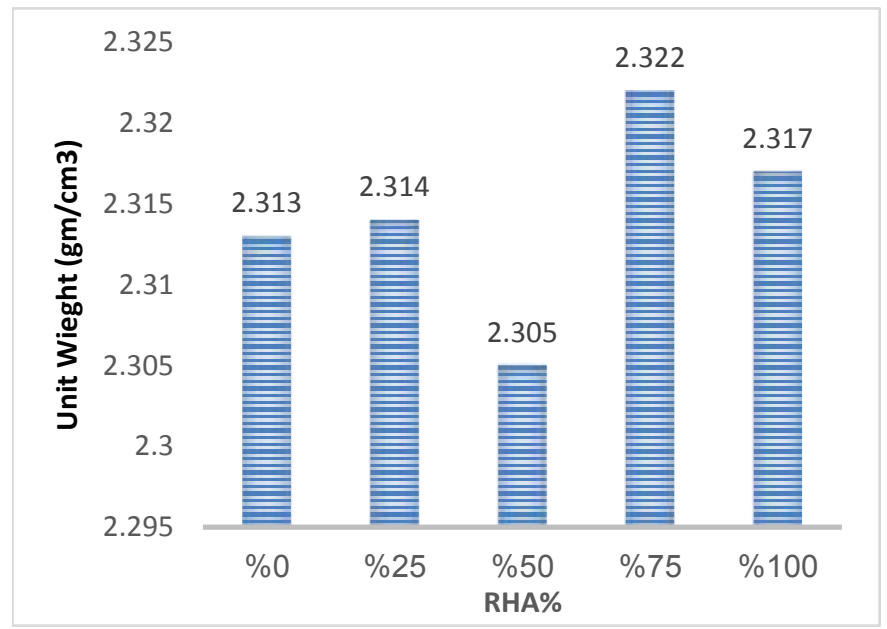

Fig. 9. \% RHA vs. Unit weight $\left(\mathrm{gm} / \mathrm{cm}^{3}\right)$ at $\mathrm{OBC} \%$
Referring to the results presented in Table (5), it was found that Marshall stability values increased by an increase in RHA percentages as shown in Figure (4) up to $75 \%$ RHA. The highest stability value recorded at $75 \%$ RHA by $9.72 \%$. Also, the results of all Marshall parameters (AV\%, VMA\%, Unit Weight and Flow) meet the specification limits according to Egyptian standards [21] as presented in Table (6). On the other hand, at 50\% RHA the increase in Marshall stability was $7.31 \%$, which is more suitable as its MQ value was 481.40 $\mathrm{kg} / \mathrm{mm}$ as MQ rang is $200-500 \mathrm{~kg} / \mathrm{mm}$ according to Specification of Ministry of Road Transport and Highways MoRT\&H, 2013 [15]. Also, adding RHA changed the OBC which increased slightly compared to control mix due to the increasing in bitumen consumption as RHA is finer than LSD which lead to an increase in surface area of mineral filler.

\section{B. Moisture Susceptibility Results}

Figure (10) shows the results of retained stability (Loss of Stability) for all mixtures. The results indicate that a significant change in LOS values occurred in the modified specimens after adding RHA to HMA. Resistant to moisture damage enhanced by using RHA in asphaltic mixtures. The highest improvement value recorded at $100 \%$ RHA. This may be due to the improvement of mixture stiffness which leads to an increase in the resistance against cracks and failure. The specification limit for LOS is $20 \%$ as maximum.

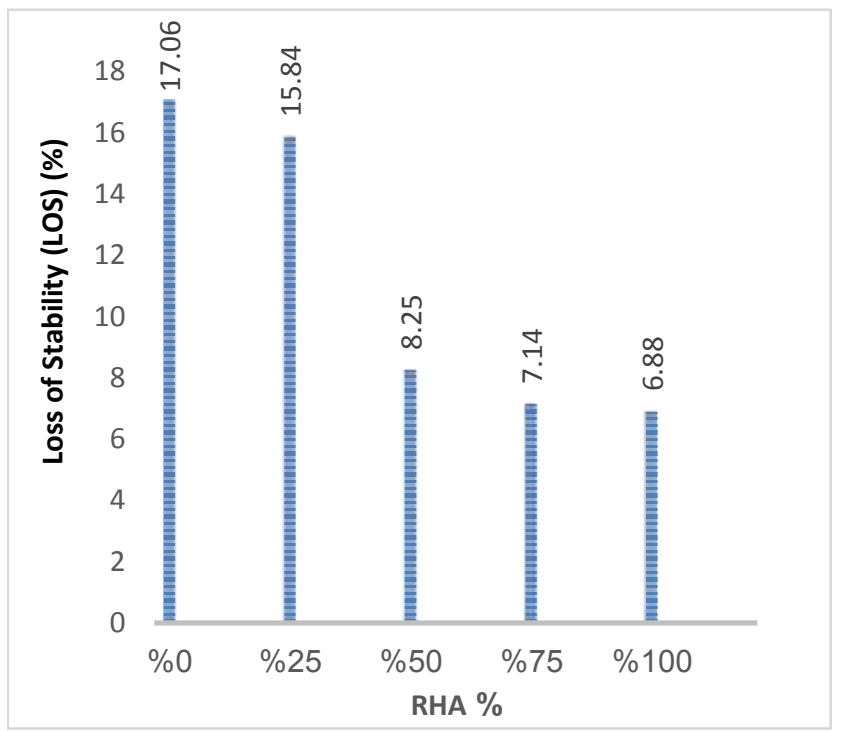

Fig. 10. LOS for Control and Modified Specimens

\section{Indirect Tensile Strength Test Results}

The Indirect Tensile Strength (ITS) Test was carried out on both control and modified specimens as shown in Figure (11). Adding RHA increased ITS values at 50\% and $75 \%$ RHA at dry conditions, while these values at $25 \%$ and $100 \%$ were lower than the conventional mix. The enhancement of ITS value recorded at 50\% RHA at dry conditions by $5.70 \%$. As same as in submerged conditions, specimens with $50 \%$ and $75 \%$ RHA gave better results than $25 \%$ and $100 \%$. Specimens contained 50\% RHA enhanced the ITS value by $9.57 \%$ at submerged conditions.

Figure (12) shows the values of tensile strength ratio 
(TSR) for all specimens. From the data presented, it can be concluded that the highest value occurred at $100 \%$ RHA as an individual value as its value in indirect tensile strength test was lower than the control specimen. Also, it should be mentioned that all results meet the specification limit for TSR. Which is $80 \%$ minimum. TSR value at $50 \%$ RHA was $85.46 \%$ and this value is acceptable to choose it as the optimum value of RHA.

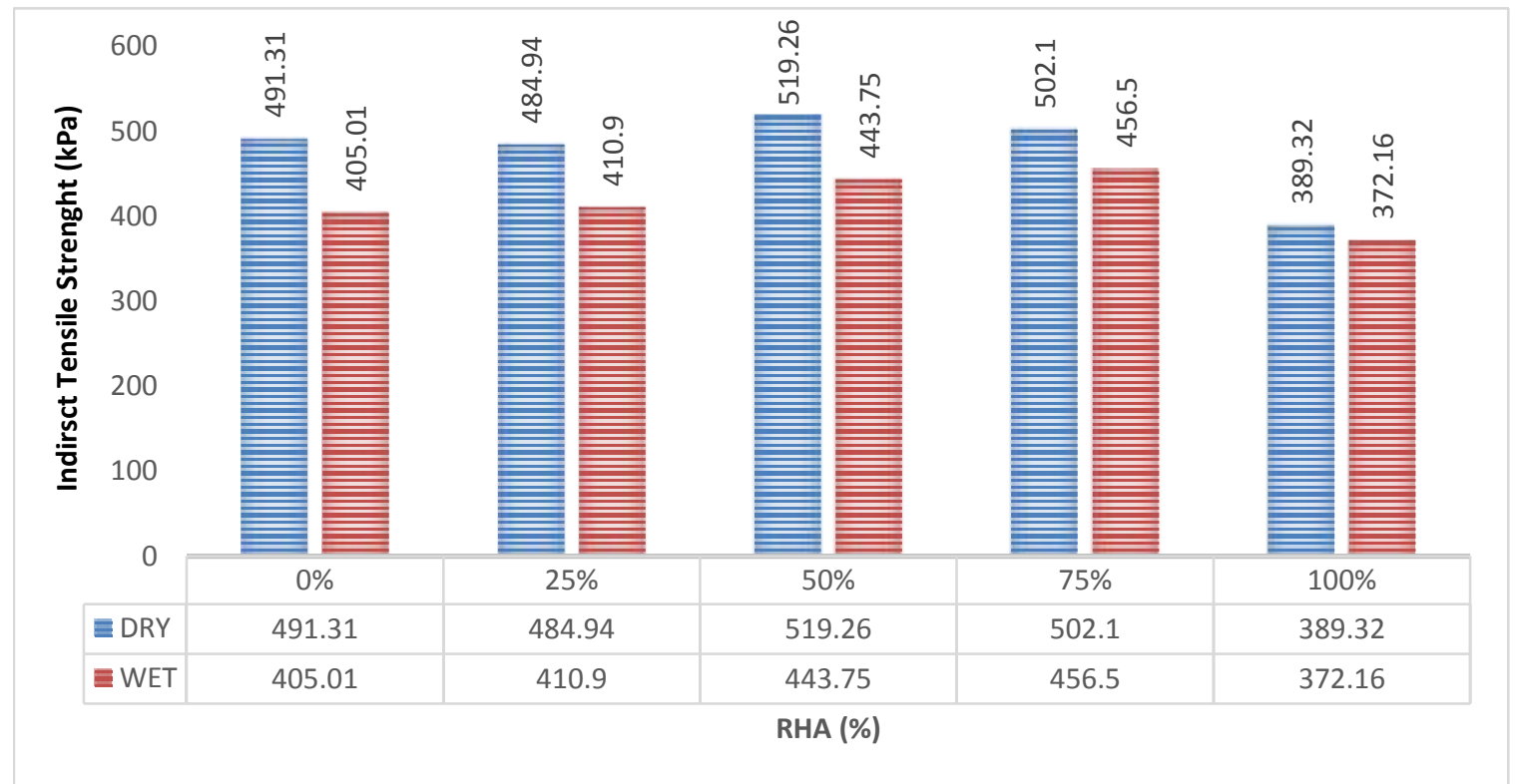

Fig. 11. Indirect Tensile Strength ITS Values for both Dry and Submerged Specimens

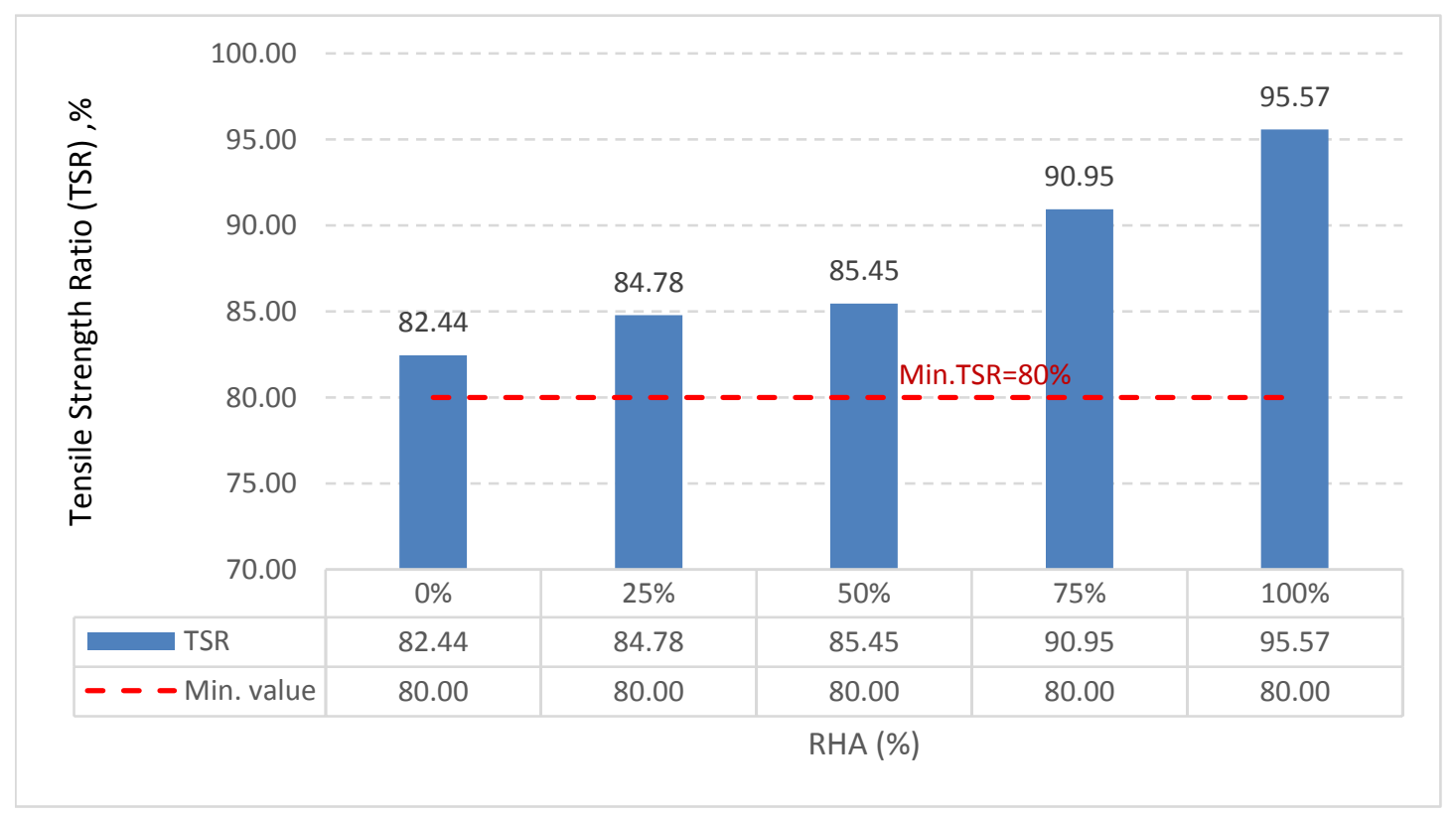

Fig. 12. Tensile Strength Ratio (TSR) for All Mixtures

\section{Wheel Tracking Test Results}

Figure (13) shows the relation between rut depth in $\mathrm{mm}$ and the number of cycles for the all mixes. While Figure (14) shows the maximum rut depth at different percentages of RHA. Results of wheel tracking test showed that a significant improvement occurred by adding RHA to asphalt mixes. Adding 50\% RHA yielded the highest reduction in the rut depth compared to other modified mixes as shown in Figure (14). 


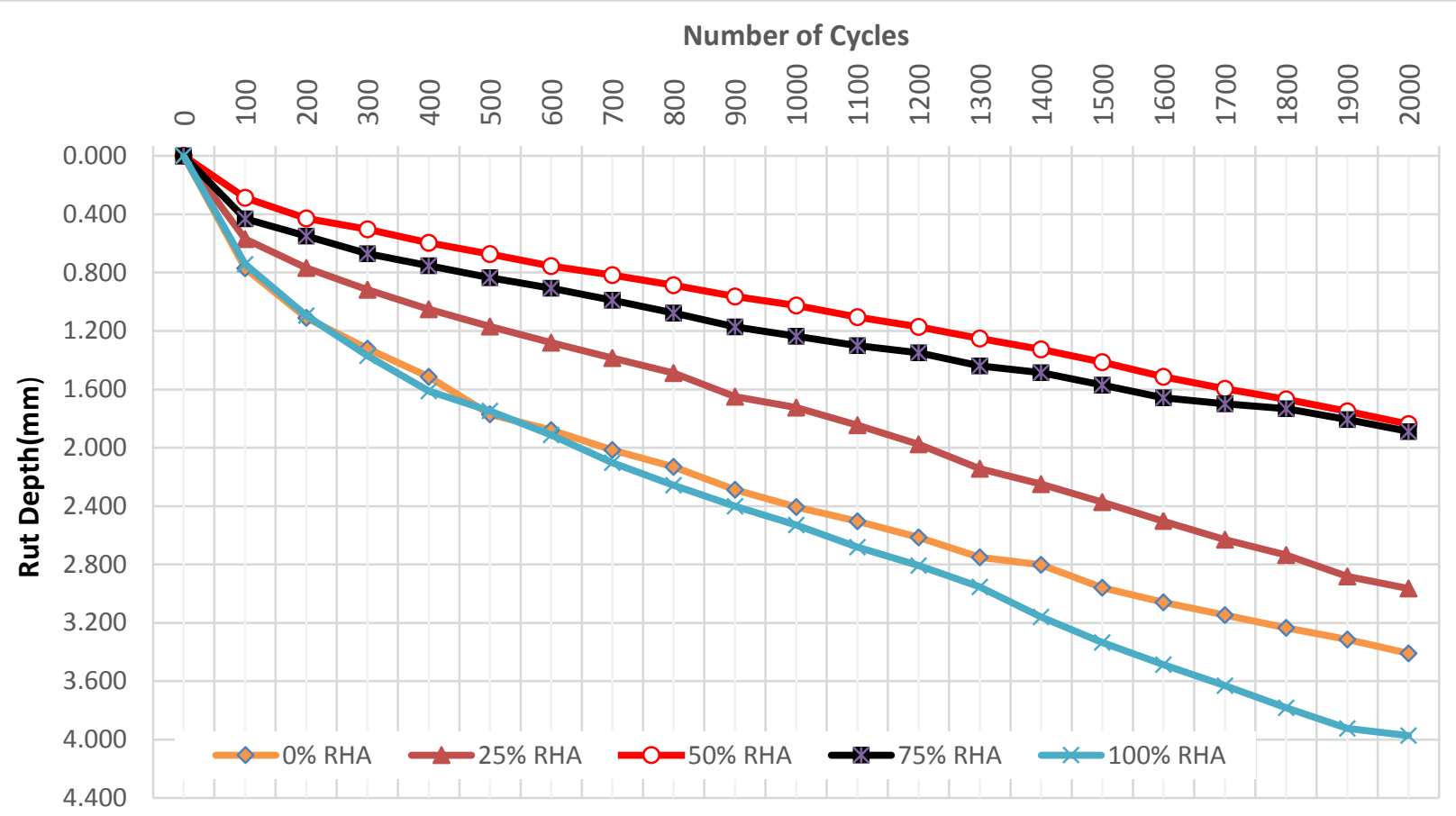

Fig. 13. Rut Depth (mm) vs. Number of Cycles

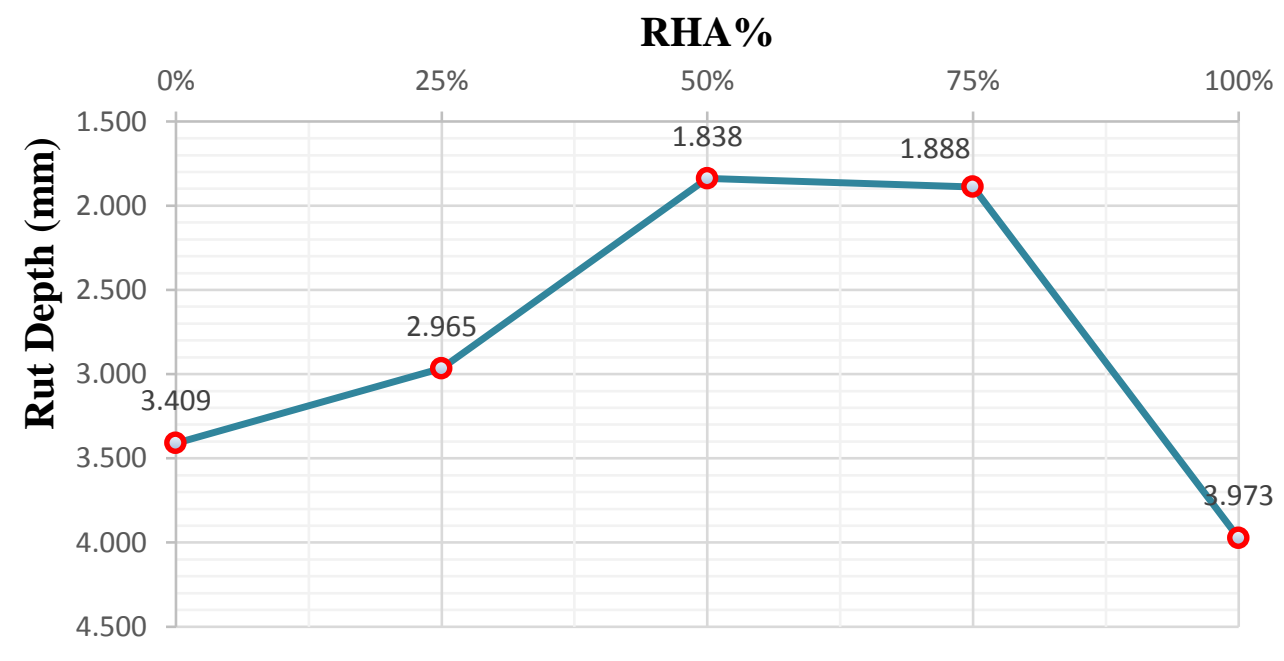

Fig. 14. Maximum Rut Depth (mm) vs. RHA\%

E. Dynamic Modulus (|E*|) and Flow Number (FN) Tests Results.

Figure (15) shows the results values of dynamic modulus for both control and modified mixtures. The Master curve for each mixture was developed by shifting values about the reference temperature $21.1^{\circ} \mathrm{C}$. $\left(70{ }^{\circ} \mathrm{F}\right)$. 


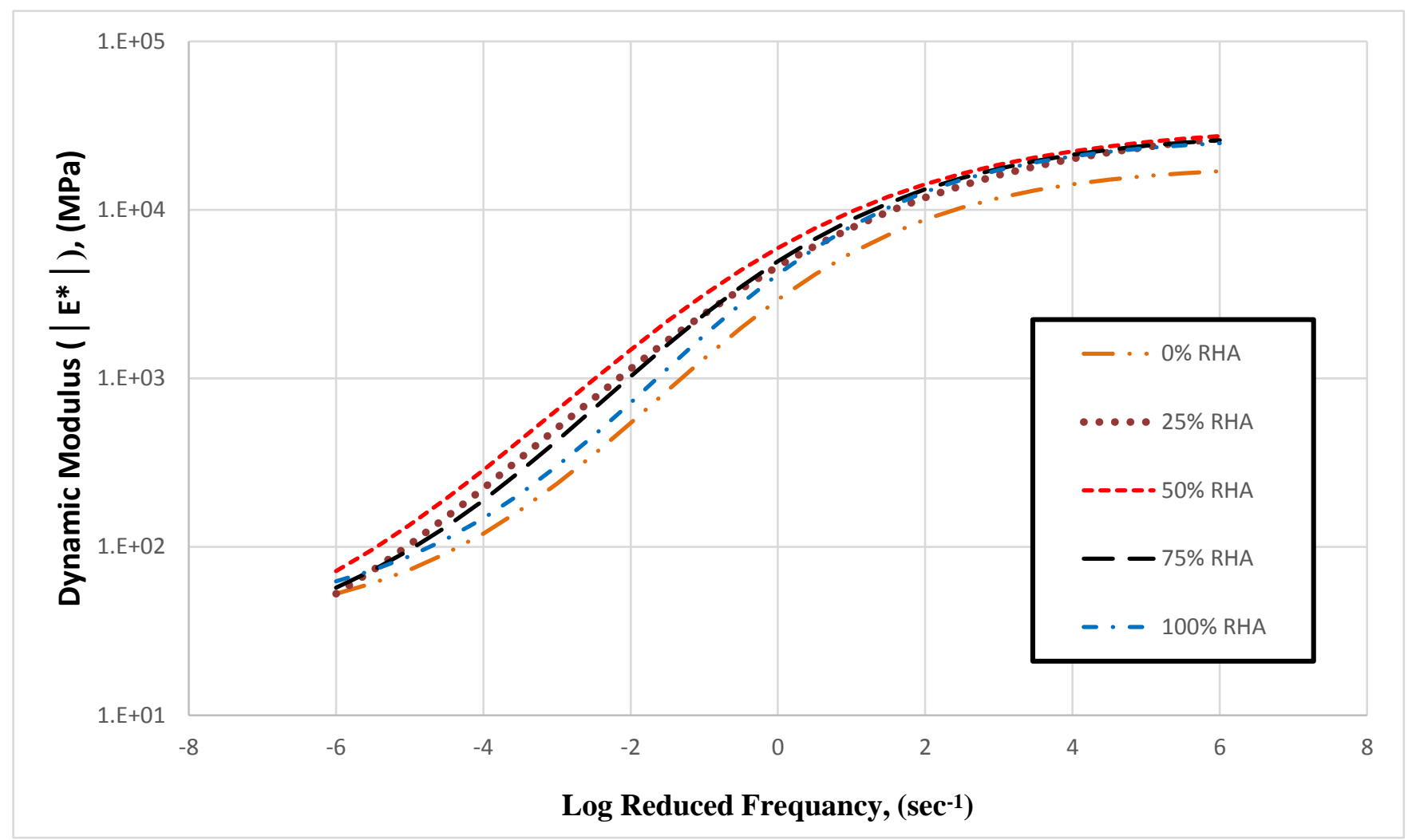

Fig. 15. Master Curve for Different Mixtures

From the previous figure, it was found that mixtures which contain RHA provide better performance than the control mixture. The results indicated that adding RHA significantly increased the values of $\left|E^{*}\right|$ compared to control mix. These results indicated that adding RHA to HMA improved the performance of the modified mixes against rutting and cracks at different temperatures and frequencies. These results are compatible to those obtained from Marshall, indirect tensile and wheel tracking tests. The highest value of $\left|E^{*}\right|$ was found at 50\%RHA which reinforce that it can be considered the optimum percentage of RHA. While Figure (17) shows the results of Flow Number $(\mathrm{FN})$ for different mixtures. Also, it was found that the performance of HMA enhanced by adding RHA. FN test is a direct indication of the rutting resistance as shown in Figure (16). As shown in Figure (16), the highest value of FN was determined at 50\% RHA compared to other RHA\%. These results confirm the wheel tracking test values which consider the optimum percentage of RHA can resist rutting was 50\%. Figure (17) shows accumulated permanent strain against number of loading cycles. The results showed that mixtures contain 50\% RHA gave the best performance against rutting compared to control and other RHA\%. 


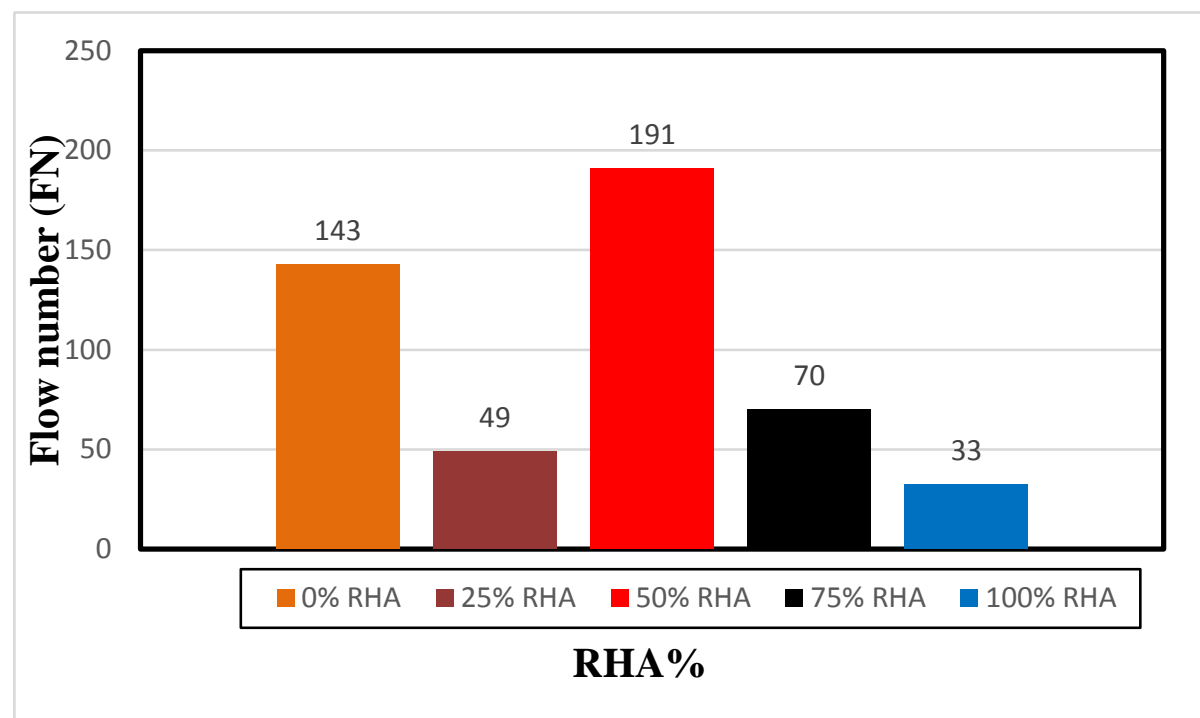

Fig. 16. Flow Number (FN) vs. \%RHA

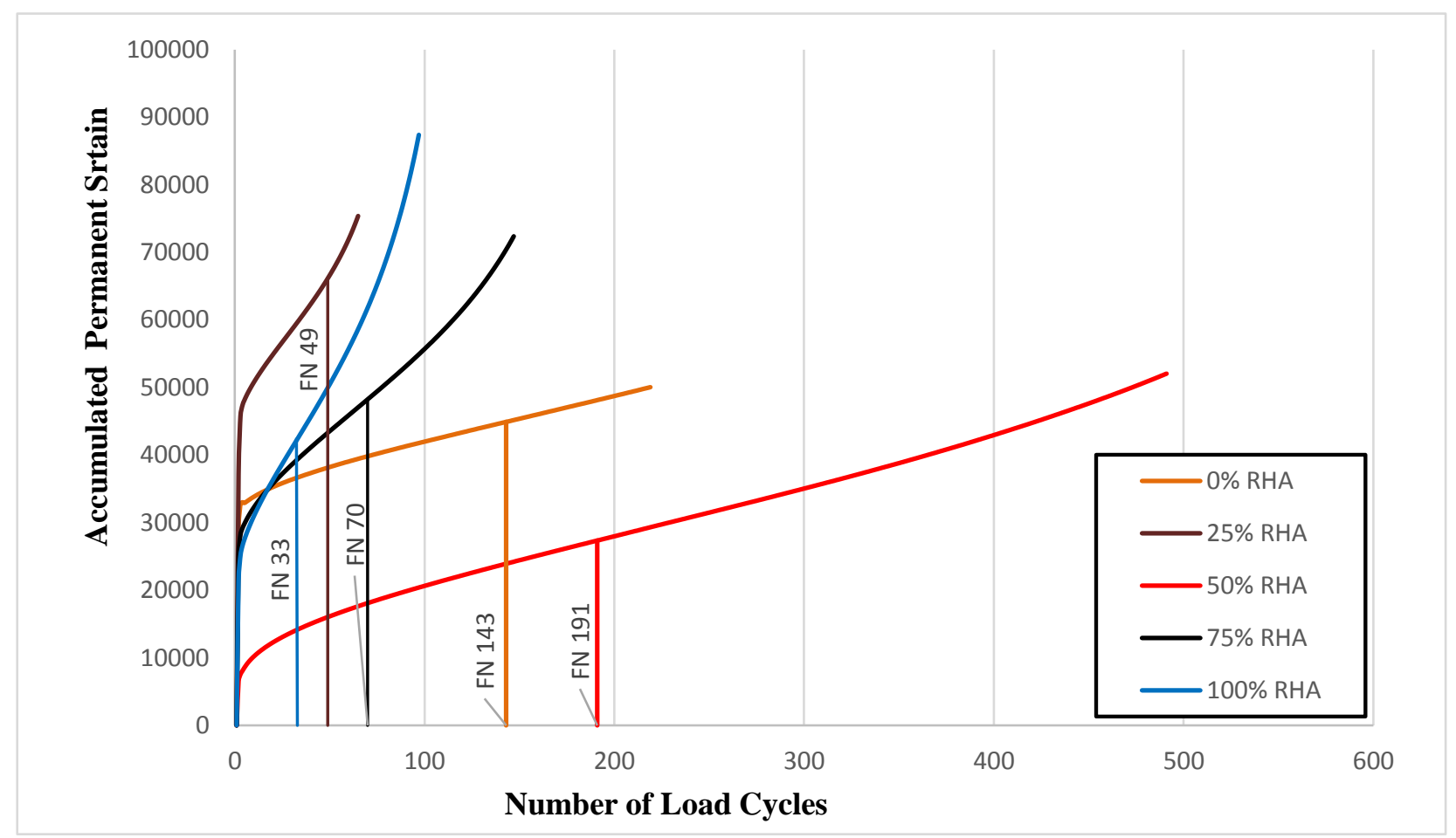

Fig. 17. Accumulated Permanent Strain vs. Number of Cycles (FN) for Different Mixtures.

Using RHA in asphalt mixes manufacturing has significant advantages. The results indicated that favorable changes in the engineering properties as presented in the previous tests were found. From the results, adding 50\% RHA is considering the optimum RHA percentage as increasing RHA content lead to an increase in binder consumption. The improvement occurred in modified mixes may be due to the increase in amount of

\section{CONCLUSIONS}

This research showed that RHA can be used in asphaltic concrete pavement, to fully or partially replace mineral filler (LSD). All investigated RHA mixes produced acceptable values for all evaluated tests according the Egyptian standards using 4Cdense graded mix. Adding RHA to HMA enhanced
RHA compared to LSD as its lower specific gravity and the higher amount of $\mathrm{SiO} 2$ which react with other materials in mixture and increase the strength. The presences of RHA increase the surface area of filler in HAM and improve the mechanical properties.

the engineering properties as ITS, and rutting resistance. Also, Marshall parameters were improved by adding RHA compared to control mixture. The experimental results showed that RHA-50\% is the optimum percentage for engineering conditions that potentially to be used as substitution of LSD. 
Also, adding RHA to HAM increased $\left|E^{*}\right|$ and FN values which indicate that the performance of hot asphalt mixtures against cracks and rutting has been improved.

\section{REFERNCES}

[1] J. Scherocman, "Stone mastic asphalt reduces rutting," Better Roads, vol. 61, 1991.

[2] J. A. Scherocman, "Construction of Stone Mastic Asphalt Test Sections in the US (With Discussion)" Journal of the Association of Asphalt Paving Technologists, vol. 61, 1992.

[3] Ş. Sargın, M. Saltan, N. Morova, S. Serin, and S. Terzi, "Evaluation of rice husk ash as filler in hot mix asphalt concrete," Construction and Building Materials, vol. 48, pp. 390-397, 2013.

[4] B. H. Goh, P. Sunnasee, K. H. Chin, B. G. Kang, and S. T. Kok, "Utilisation of Rice Husk Ash in Asphaltic Concrete Pavement," Advanced Materials Research, vol. 1030-1032, pp. 961-964, 2014.

[5] J. A. Sadeeq, J. M. Kaura, O. Joshua, and A. Rabilu, "Recycling of reclaimed asphalt pavement (rap) with rice husk ash (rha)/ordinary portland cement (opc) blend as filler," Jordan Journal of Civil Engineering, vol. 159, pp. 1-9, 2014.

[6] A. Behnood, M. Modiri Gharehveran, F. Gozali Asl, and M. Ameri, "Effects of copper slag and recycled concrete aggregate on the properties of CIR mixes with bitumen emulsion, rice husk ash, Portland cement and fly ash," Construction and Building Materials, vol. 96, pp. 172-180, 2015.

[7] A. Al-Hdabi, "Laboratory investigation on the properties of asphalt concrete mixture with Rice Husk Ash as filler," Construction and Building Materials, vol. 126, pp. 544-551, 2016.

[8] R. Mistry, S. Karmakar, and T. Kumar Roy, "Experimental evaluation of rice husk ash and fly ash as alternative fillers in hot-mix asphalt," Road Materials and Pavement Design, vol. 20, pp. 979-990, 2019.

[9] A. A. Abdelmagid and C. Pei Feng, "Evaluating the Effect of Rice-Husk Ash and Crumb-Rubber Powder on the High-Temperature Performance of Asphalt Binder," Journal of Materials in Civil Engineering, vol. 31, p. 04019296, 2019.
[10] A. Ameli, R. Babagoli, N. Norouzi, F. Jalali, and F. P. Mamaghani, "Laboratory evaluation of the effect of coal waste ash (CWA) and rice husk ash (RHA) on performance of asphalt mastics and Stone matrix asphalt (SMA) mixture," Construction and Building Materials, vol. 236, p. $117557,2020$.

[11] R. Akter and M. K. Hossain, "Influence of Rice Husk Ash and Slag as Fillers in Asphalt Concrete Mixes," American Journal of Engineering Research (AJER) Volume-6, Issue-1, pp-303-311, 2017.

[12] K. R. a. j. P.R., "Review paper on Use of Rise Husk Ash as mineral filler in Mastic Asphalt," International Research Journal of Engineering and Technology (IRJET), vol. 05 Issue: 03- Mar- India, 2018.

[13] R. P. Jaya, M. M. Satar, N. Abdullah, M. Hainin, N. A. Hassan, H. Yaacob, et al., "Effect of Black Rice Husk Ash on Asphaltic Concrete Properties under Aging Condition," in IOP Conference Series: Materials Science and Engineering, 2018, p. 032003.

[14] ASTM(D6927-15), "Standard Test Method for Marshall Stability and Flow of Asphalt Mixtures," in ASTM International: West Conshohocken, PA, USA, ed, 2015.

[15] MoRT\&H, Specification of Ministry of Road Transport and Highways, Specification for Roads and Bridge Works, IV Revision, Indian Roads Congress, New Delhi, India, 2013.

[16] ASTM(D1559-89), "Standard test method for resistance to plastic flow of bituminous mixtures using Marshall Apparatus. Annual Book of ASTM Standards USA," ed, 2003.

[17] ASTM(D6931), "Standard test method for indirect tensile (IDT) strength of bituminous mixtures. ASTM, West Conshohocken, PA," ed, 2012.

[18] ASTM(D4867M-09), "Standard test method for effect of moisture on asphalt concrete paving mixtures," in Annual book of ASTM standards, ed, 2014.

[19] AASHTO(T324), "Standard method of test for Hamburg wheel-track testing of compacted hot mix asphalt (HMA)," ed: AASHTO Washington, DC, 2011.

[20] AASHTO(TP62), "Standard method of test for determining dynamic modulus of hot-mix asphalt (HMA)," in Am. Asoc. State Highway Transp. Officials, ed, 2007.

[21] EcP 2008, Egyptian Code for Urban and Rural Roads , No104-2008 , Part 4 -104/2008, Page 130, 2008. 